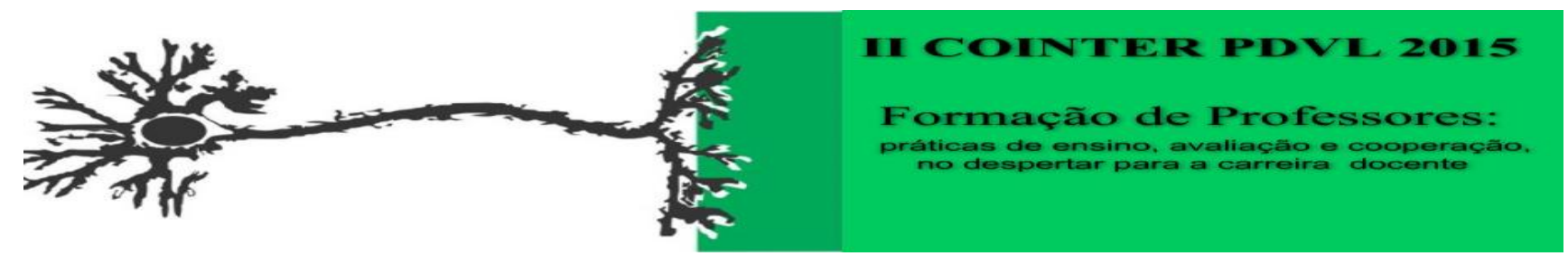

\title{
DESCONSTRUINDO PARADIGMAS SOBRE A PROFISSÃO DE PROFESSOR: PERCEPÇÃO DO OFÍCIO PELOS ALUNOS DA ESCOLA E.E.F.M. MARCOS BISPO DA SILVA EM JI-PARANÁ- RO.
}

\author{
Apresentação: Pôster
}

\begin{abstract}
Andrômeda Serpa Hermano de Souza ${ }^{1}$; Vânia Costa Ferreira Vanuchi ${ }^{2}$ José Antonio Avelar Baptista $^{3}$; Renato André Zan ${ }^{4}$
\end{abstract}

\section{Introdução}

A falta de professores de algumas áreas específicas no Brasil tem se tornado motivo de preocupação, cada vez menos jovens optam pelos cursos de licenciatura no país, um problema que pode ter sido gerado por diversas causas, dentre elas: a falta de informação sobre a profissão, a ideia fixa que há baixa remuneração, a falta de atratividade, e o mais importante a falta de incentivo por inúmeros sujeitos influentes no cotidiano desse educando (PEREIRA, 1999). A desvalorização da profissão se dá pela nova concepção de mundo, de homem, a formulação das políticas públicas e também as leis do mercado em vigor (FACCI, 2004). Segundo Sacristán e Gómez (1998, p. 63) é a escola o elemento principal para orientação nos processos educativos, é através dela que se promove o incentivo, estimulo, a compreensão, o raciocínio, que favorecem uma reconstrução de conceitos nos alunos. O presente trabalho se justifica por esclarecer sobre a profissão de professor, atuando como um papel incentivador, com iniciativa de retirada de dúvidas sobre a mesma, ainda sim na sondagem de como o oficio tem sido considerado atualmente e por fim entender o porquê cada vez menos as licenciaturas não são tão almejadas.

\section{Fundamentação Teórica}

De acordo com o Relatório da Organização para Cooperação e Desenvolvimento Econômico - OCDE (2006), que contém dados de diversos países, nos revela que no Brasil a uma grande escassez na formação de professores em algumas áreas, má qualidade na formação e abandono do curso, dados que preocupam bastante no que diz respeito a educação brasileira. Se analisarmos, a

\footnotetext{
${ }^{1}$ Graduanda em Licenciatura em Química, Instituto Federal de Rondônia - IFRO, serpa_shs266@hotmail.com

${ }^{2}$ Graduanda em Licenciatura em Química, Instituto Federal de Rondônia - IFRO, vaniakeel@hotmail.com

${ }^{3}$ Dr. Em Química, Prof. EBTT em Química, Instituto Federal de Rondônia - IFRO, jose.antonio@ifro.edu.br

${ }^{4}$ Doutorando em Química de Produtos Naturais IPPN-UFRJ, Prof. EBTT em Química, Instituto Federal de Rondônia IFRO, renato-zan@hotmail.com
} 
escolha da profissão não se dá apenas pelas características pessoais, mas também pelo contexto histórico e o ambiente social em que vive esse jovem (Bock, 2002). Jesus (2004) afirma que a nova visão a qual deprecia a profissão se deve ao fato da alteração do verdadeiro papel do professor na escola, onde anteriormente era o único espaço em que se podia aprender. Outro fator que contribui com esse baixo índice de formação é a falta de incentivo para a profissão, como afirma Rangel (1994), o bom professor é aquele que é amigo, que ensina, esclarece, que corrige, que estimula e orienta. Nesse sentido afirma Vasconcellos (1998) que o próprio professor não tem a dimensão da importância do seu trabalho e da influência e complexidades que esse trabalho implica. De acordo com esse ponto de vista existem duas faces da moeda no que se diz respeito a educação, por um lado profissionais preocupados com a educação que apresenta bons resultados no esforço de seu trabalho e por outro lado aqueles que por acomodação não se envolve nas práticas pedagógicas e ainda disseminam uma imagem ruim dos próprios colegas e da própria profissão (GENTILE, 2001 apud PINTO, 2012)

Escolher o curso de licenciatura envolve vários motivos e competências, pois o professor atua para realizar com excelência suas tarefas, estabelece relações com pessoas, tem impacto sobre seus pensamentos e visões, atuando como um verdadeiro motivador (REGO et al.,2005). Por fim toda prática educativa deve conduzir o homem a reflexão de seu papel no mundo, sendo capaz de mudar o mundo e a si próprio (FREIRE, 1974).

\section{Metodologia}

O trabalho foi realizado por acadêmicas do curso de licenciatura em química na escola E.E.F.M. Marcos Bispo da Silva com os alunos do terceiro ano do ensino médio. A ideia principal deste trabalho foi primeiramente romper com os paradigmas errôneos que muitos acreditam sobre a profissão do professor, esclarecer duvidas através de palestras vocacionais e nortear os alunos em suas futuras escolhas acadêmicas, visto que, muitos alunos que estão no ensino médio ainda não sabem qual carreira seguir, incentivar os alunos para as licenciaturas a partir das experiências pessoais vivenciadas no curso, assim despertando o interesse dos mesmos em optar por elas. Durante a palestra foram apontados o papel do professor, as vantagens de ser professor e também apresentado um vídeo sobre como é cursar licenciatura em química, para levantamento de dados, os alunos responderam um questionário sobre o que achava da profissão.

\section{Resultados e Discussões}

Participaram da palestra cerca de 35 alunos do $3^{\circ}$ ano do ensino médio ( imagem 01), porém 
somente 17 alunos (48,6\%) aceitaram responder o questionário. Desses 17 alunos, 100\% respondeu que acham muito importante a profissão de professor, 3 alunos (17.6\%) disseram que não tem nenhuma vontade de ser professor, $11(64,8 \%)$ disseram que tem pouca vontade de ser professor e 3 $(17,6 \%)$ disseram que tem muita vontade de ser professor. Dos que responderam ter vontade ou pouca vontade ser professor, 50\% dos alunos querem ser professores de biologia, 14,3\% de matemática, e 21,4\% de português, história ou artes e 14,3 \% não responderam. 9 (52,9\%) responderam que não são incentivados a serem professores, $6(35,3 \%)$ disseram que são pouco incentivados, $2(11,8 \%)$ que são muito incentivados. Dos que responderam serem incentivados $50 \%$ disseram receber apoio da família e 50\% dos próprios professores. $6(35,3 \%)$ responderam ter dificuldades para aprender os conteúdos de química e 11 (64,7\%). Dos que responderam ter dificuldades, $66.8 \%$ tem dificuldades com matemática e decorar muitas fórmulas, 16,6\% em entender questões da prova e 16,6\% não responderam. E por fim $2(11,7 \%)$ disseram não ter interesse de conhecer mais sobre a profissão, $9(53 \%)$ disseram ter pouco interesse e $6(35,3 \%)$ disseram ter muito interesse em conhecer.

Imagem 1: Palestra sobre as vantagens de ser professor. Fonte: Próprios autores

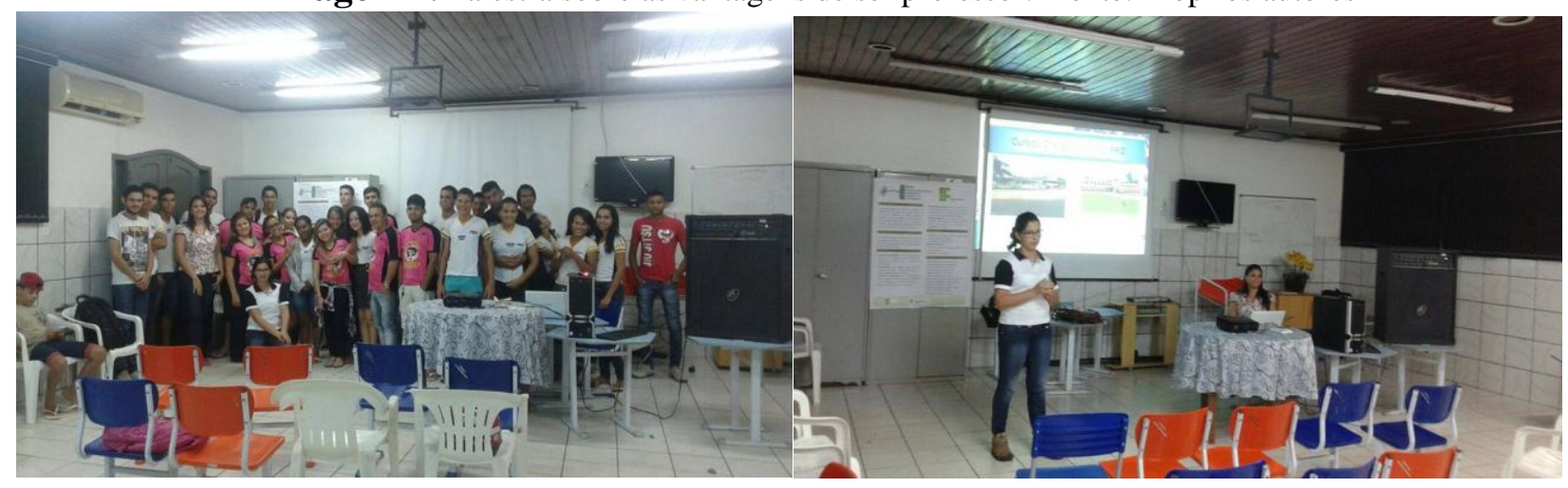

\section{Conclusões}

Analisando os índices é possível concluir que pouco se observou de motivação a carreira docente, poucos alunos entendem sobre a profissão, e muitos deles demonstram pouca importância ao saber mais sobre ela, quando são motivados, é por algum familiar que é professor ou algum professor que realmente gosta do que faz. Apesar dos resultados existem muitas outras causas de o índice pelo interesse da profissão serem tão baixos, muitos deles, pelo o que se pode observar, advém por motivos de cunho pessoal, pois alguns alunos já têm definido a carreira que pretende seguir. No mais através do diálogo observou-se que pouco se sabe sobre ser professor, porém todos conhecem a importância do oficio, o que ainda não é suficiente para motivar os alunos a 
ingressarem nas licenciaturas, necessitando haver mais práticas motivadoras e de incentivo para que esses alunos possam se interessar e não somente ingressar no curso, mas permanecer e fazer a diferença na educação.

\section{Referências}

BOCK, S. D. A Escolha profissional de sujeitos de baixa renda recém-egressos do ensino médio. 2008. Tese (Doutorado) - Faculdade de Educação, Unicamp, Campinas.

FACCI, M.G.D. Valorização ou esvaziamento do trabalho do professor? Um estudo crítico comparativo da teoria do professor reflexivo, do construtivismo e da psicologia vigotskiana. Campinas: Autores Associados, 2004. (Coleção formação de professores).

FREIRE, Paulo. Educação como prática da liberdade. Rio de Janeiro: Paz e Terra, 1974.

GENTILE apud PINTO, A. N; Desconstruindo Paradigmas. Rio de Janeiro. 2012.

JESUS, S. N. Desmotivação e crise de identidade na profissão docente. Revista Katálysis, Florianópolis, v. 7, n. 2, p.192-202, 2004.

OCDE. Professores são importantes: atraindo, desenvolvendo e retendo professores eficazes. São Paulo: Moderna, 2006.

RANGEL, Mary Representações e reflexões sobre o bom professor, 2ª . ed.Vozes, 1994

PEREIRA, J.E.D. As licenciaturas e as novas políticas educacionais para a formação docente. Educação e sociedade v.20 n.68, 1999.

RANGEL, Mary Representações e reflexões sobre o bom professor, 2ª ed.Vozes, 1994.

REGO, Armênio et al. Os motivos de sucesso, afiliação e poder: perfis motivacionais de estudantes de graduação e pós-graduação e sua relação com níveis remuneratórios. Psicol. Reflex. Crit. v. 18 n.2 Porto Alegre Maio/agosto 2005

SACRISTÁN, J. G.; GÓMEZ, A. I. P. Compreender e transformar o ensino. Porto Alegre: ArtMed, 1998.

VASCONCELLOS, Celso dos S. Resgate do professor como sujeito de transformação: para onde vai o professor? 6 ed. São Paulo, Libertad, vol. 1, 1998 